\title{
Material, Compressional and Tableting Properties of Ipomea Batatas (Sweet Potato) Starch Co-Processed with Silicon Dioxide
}

\author{
Lateef Bakre $^{1 \star}$, Damola Osibajo ${ }^{1}$, Gbenga Koiki ${ }^{1}$, Oluyemisi Bamiro ${ }^{1}$ \\ 1 Department of Pharmaceutics and Pharmaceutical Technology, Faculty of Pharmacy, Olabisi Onabanjo University, \\ Nigeria
}

\begin{abstract}
This study aims to co-process native Ipomea batatas starch (NPS) with colloidal silicon dioxide and evaluate the properties of the co-processed excipient (CPS). The powder morphology was determined by scanning electron microscopy (SEM), differential scanning calorimetry (DSC) and X-Ray Diffraction (XRD) measurements. The compressional, mechanical and release properties of metronidazole tablet formulations were evaluated. NPS was predominantly oval in shape while CPS had more large truncated ellipsoidal granules. Both NPS and CPS exhibited spectra typical of a Type A XRD pattern, but CPS has a sharp peak with strong intensity at $27^{\circ} 2 \theta$ which was absent in NPS. Although NPS had a faster onset of plastic deformation, the overall amount of plastic deformation was higher in CPS. Tablets formulated with CPS had faster dissolution than those containing similar concentration of NPS. The co-processing of Ipomea batatas starch with colloidal silicon dioxide resulted in modification of its powder and tableting properties.
\end{abstract}

Keywords: Co-processing, Ipomea batatas starch, powder and compressional characteristics, tableting properties.

\section{INTRODUCTION}

Excipients play an important role in drug delivery and in the formulation of a stable and safe dosage form. International Pharmaceutical Excipients Council (IPEC) defines excipients as "substances, other than the API, in finished dosage form, which have been appropriately evaluated for safety and are included

${ }^{*}$ Corresponding Author: Lateef Bakre, e-mail: lateef.bakre@oouagoiwoye.edu.ng Lateef Bakre ORCID Number: https://orcid.org/0000-0003-1222-1057 Damola Osibajo ORCID Number: https://orcid.org/0000-0001-7557-7654 Gbenga Koiki ORCID Number: https://orcid.org/0000-0001-6774-0597 Oluyemisi Bamiro ORCID Number: https://orcid.org/0000-0002-6032-6075 (Received 12 March 2019, accepted 05 June 2019) 
in a drug delivery system to either aid the processing or to aid manufacture, protect, support, enhance stability, bioavailability or patient acceptability, assist in product identification, or enhance any other attributes of the overall safety and effectiveness of the drug delivery system during storage or use" ${ }^{1}$. In recent years, scientists have directed their studies at developing novel excipients with multifunctional applications which helps to lower production cost because some stages in production and excipients are eliminated ${ }^{2,3}$. To achieve this, a particle engineering technique called co processing was introduced and this has gained wide acceptance over the years. Co-processing involves combining two or more existing excipients through interaction at the sub-particle level and does not result in the formation of covalent bonding. It brings about a functional synergy and masks the undesirable qualities of the individual components. The co-processed excipients have new functionalities that cannot be achieved by simple physical mixture of individual components ${ }^{4,5}$.

A survey of the literature reveals that a number of excipients have been co-processed with resultant enhanced functionalities ${ }^{6,7,8,9}$. However, there appears to be no information on co processing of potato starch with silicon dioxide. Starch has been widely used as excipients (disintegrants, binders, glidants, fillers, thickeners and bulking agents) in the food and pharmaceutical industries ${ }^{10}$. As a result of this versatile application of starch in drug formulations, it is necessary to continuously develop new starch excipients with improved functionalities with a view to meeting specific needs of drug formulators. Colloidal silicon dioxide is employed as a glidant in formulations to enhance powder flow. It has the ability to coat materials and thereby reduces forces of attraction (van der Waals) within particles. In addition, it absorbs water molecules present on hygroscopic powders and thus minimizes clumping and caking. These two properties prevent the development of "bridges" within the powder and thus improve flow through hoppers during tableting. The purpose of this investigation was to co-process potato starch with silicon dioxide and evaluate the powder, compressional and tableting properties of the co-processed excipient.

\section{METHODOLOGY}

\section{Materials}

The following materials were used: Metronidazole (DMV, Veghel, Netherlands), colloidal silicon dioxide (CAB-O-SIL $\AA$, CABOT GmbH, Germany), corn starch and magnesium stearate (BDH Chemical, Poole, UK). The potato starch was prepared in the laboratory and analytical grade chemicals were used in the study. 


\section{Preparation of potato starch}

Starch was obtained by the method of Alebiowu ${ }^{11}$ with slight modification. The fresh sweet potato tubers were washed, peeled, cut into small pieces, soaked in distilled water for $24 \mathrm{hrs}$ and thereafter homogenized in a blender to obtain a slurry. This was filtered using a muslin cloth and the filtrate was allowed to stand for 5 hours to allow for the starch to settle. The sediment was centrifuged, the supernatant discarded, and the crude starch cake was washed repeatedly with distilled water to further remove impurity. The purified starch cake was air dried, pulverized into fine powder and kept in air tight container for further use.

\section{Preparation of co-processed starch}

The co-processed starch was prepared by the method of Mshelia et.al. ${ }^{7}$ A 100 $\mathrm{g}$ of a suspension containing $40 \% \mathrm{w} / \mathrm{w}$ of potato starch was prepared in a 500 $\mathrm{mL}$ capacity beaker by adding $250 \mathrm{~mL}$ of distilled water. $2.04 \mathrm{~g}$ of silicon dioxide was then dispersed in the suspension and constantly stirred for $10 \mathrm{~min}$ before heating in a water bath at $50 \pm 2{ }^{\circ} \mathrm{C}$ for 20 mins. The co-processed starch was washed with $99 \%$ ethanol, passed through a $0.8 \mathrm{~mm}$ sieve size, air dried and then kept in an air-tight container until ready for use.

\section{Fourier transmission infrared spectra (FT-IR) spectroscopy.}

The samples were dried and kept in a desiccator before the FTIR analysis. Spectra were obtained by using potassium bromide discs obtained from a mixture of the starch and dry potassium bromide on a FT-IR spectrophotometer (BX 273, Perkin-Elmer, USA).

\section{Differential scanning calorimetry (DSC)}

DSC thermograms of the sample were determined on a Mettler instrument (DSC1, Toledo, USA). A 4-10 mg weight of sample were compressed into pellets in an aluminium pan and heated from 30 to $430{ }^{\circ} \mathrm{C}$ at a rate of $20^{\circ} \mathrm{C} / \mathrm{min}$ under inert nitrogen atmosphere with a flow rate of $20 \mathrm{mLmin}^{-1}$. The reference used was an empty aluminum pan.

\section{Scanning electron microscopy (SEM)}

A Scanning electron microscope ZEISS EVO18 (Germany) was used for the test. Dried starch powders were mounted in a double sided adhesive conductive carbon tape with aluminum stub and coated with gold in a sputter coater with $7 \mathrm{~mA}$ current for $90 \mathrm{~s}$. 


\section{X-Ray Diffraction Measurements:}

The XRD spectra were obtained by exposing the samples to $\mathrm{X}$ - ray beam at 40mA and $45 \mathrm{KV}$ in an X-ray diffractometer (Empyrean, PAN analytical, Netherlands). The $2 \theta$ range of $10^{\circ}-90^{\circ}$ was recorded with $0.1^{\circ}$ resolution.

\section{Determination of Swelling Capacity}

Three grams of the starch powders was added to $20 \mathrm{~mL}$ of water in a $50 \mathrm{~mL}$ ground-glass stoppered graduated cylinder and the volume noted $\left(\mathrm{V}_{\mathrm{o}}\right)$. The suspension was shaken every 10 minutes for $1 \mathrm{hr}$, allowed to stand for $5 \mathrm{hrs}$ and the volume occupied by the sample (V) was recorded. The swelling index was calculated as the ratio of $\mathrm{V}$ to $\mathrm{V}_{\mathrm{o}}$. The procedure was repeated thrice, and the result obtained was recorded as mean \pm standard deviation.

\section{Determination of particle, tapped and bulk densities}

The liquid immersion technique (pycnometer method) was used to determine the particle density with xylene as the displacement liquid according to the method of Bakre and Ajala ${ }^{12}$. The bulk density was determined by pouring a 10 $\mathrm{g}$ weight of powder into a measuring cylinder and the volume occupied noted. The bulk density was obtained as the ratio of weight (10 g) to the volume occupied. The procedure was carried out in triplicate and the mean \pm standard deviation calculated. The tapped density was obtained by tapping the sample 300 times at the rate of 38 taps in a minute ${ }^{13}$. This procedure was redone with 700 taps.

\section{Determination of porosity and flow properties}

The porosity was calculated using bulk ( $\rho$ b) and true densities ( $\rho$ s) data according to Equation 1

$$
\mathrm{e}=1-\rho \mathrm{b} / \rho \mathrm{s}
$$

The static angle of repose was determined by the funnel method. A $10 \mathrm{~g}$ quantity of powder sample was weighed and allowed to flow via a glass funnel fixed $10 \mathrm{~cm}$ above a flat surface. The radius and the height of the resultant conical heap were measured. The tangent of the ratio of the height to the radius of the conical heap was taken as the angle of repose. The values obtained from the ratio of the tapped and bulk density was taken as the Hausner ratio while the Carr's index was obtained using Equation 2 
Carr's Index $=\left\lfloor\frac{\mathrm{PT}-\mathrm{PB}}{\mathrm{PT}}\right\rfloor \times 100$

Where PT and PB are tapped and bulk densities respectively

\section{Preparation of sweet potato starch compacts}

Powder starch (500 mg) were compressed into compacts using $28 \mathrm{~N}, 56.5 \mathrm{~N}$, $84 \mathrm{~N}, 113 \mathrm{~N}, 141 \mathrm{~N}, 169 \mathrm{~N}$ and $198 \mathrm{~N}$ forces at a dwell time of 30 seconds on a tablet press (Model C, Carver Inc., USA). The lubricant used was magnesium stearate dispersion in $96 \%$ ethanol. On ejection, the tablets were stored for 24 hrs over silica gel to allow for hardening and elastic recovery. The dimensions and weights were determined within $0.01 \mathrm{~mm}$ and $\pm 1 \mathrm{mg}$ respectively. Equation 3 was used to calculate the relative densities (D) of the tablet compacts of weight W $(\mathrm{g})$, volume vt $\left(\mathrm{cm}^{3}\right)$ and particle density Ps $\left(\mathrm{g} / \mathrm{cm}^{3}\right)$

$$
\mathrm{D}=\mathrm{W} / \mathrm{vt} \times \mathrm{Ps}_{\mathrm{s}}
$$

The data obtained were used for the Heckel and Kawakita plots.

\section{Analysis of compaction data}

Heckel plot: The compressional properties were determined using the Heckel equation ${ }^{14}$

$$
\operatorname{In} \frac{1}{1-\mathrm{D}}=\mathrm{KP}+\mathrm{A}
$$

The mean yield pressure $\mathrm{P}_{\mathrm{y}}$ of the material was derived from the inverse of the slope $\mathrm{K}$ while $\mathrm{A}$ is the intercept. $\mathrm{D}_{\mathrm{A}}$ was obtained from the intercept using Equation 5:

$$
\mathrm{D}_{\mathrm{A}}=1-\mathrm{e}^{\mathrm{A}}
$$

The relative density when no pressure is applied $\left(\mathrm{D}_{\mathrm{o}}\right)$ represents the rearrangement phase due to die filling while $\mathrm{D}_{\mathrm{B}}$ (obtained from $\mathrm{D}_{\mathrm{A}-} \mathrm{D}_{\mathrm{B}}$ ) is the rearrangement phase at the early stages of compression.

Kawakita plot: The kawakita equation ${ }^{15}$ expresses the effect of applied pressure, $\mathrm{P}$ on the degree of volume reduction.

$$
\mathrm{P} / \mathrm{C}=\mathrm{P} / \mathrm{a}+1 / \mathrm{ab}
$$


The constant 'a' (obtained from the slope) is the powder porosity without compression and ' $b$ ' is a function of the ability of the material to deform plastically. $\mathrm{D}_{\mathrm{I}}(1-\mathrm{a})$ which is the initial packed relative density of the tablets pressure when small pressure is applied was obtained. $\mathrm{Pk}$ is derived from the reciprocal of $\mathrm{b}$ and it represents the pressure required to reduce the powder bed by $50 \%{ }^{16}$.

\section{Preparation of tablets}

The tablets containing $500 \mathrm{mg}$ of the powders were made by compressing the formulation (Table 1) for 30 seconds at 1.0 tonne with a tablet press (Model C, Carver Inc., USA). The lubricant used for the die and the punches was magnesium stearate dispersion in $96 \%$ ethanol. When the compression process was completed, the tablets were removed from the die and stored over silica gel.

Table 1. Formulation table for metronidazole formulations.

\begin{tabular}{lllll}
\hline & \multicolumn{4}{c}{ Formulations } \\
\cline { 2 - 5 } Ingredients $(\mathbf{m g})$ & A & B & C & D \\
\hline Metronidazole & 100 & 100 & 100 & 100 \\
\hline CPS & 250 & 200 & - & - \\
\hline NPS & - & - & 250 & 200 \\
\hline Corn Starch & 50 & 50 & 50 & 50 \\
\hline Lactose & 100 & 150 & 100 & 150 \\
\hline
\end{tabular}

\section{Evaluation of tablet properties}

The tablet hardness was determined by measuring the load required to diametrically break each of the 10 tablets using a Monsanto hardness tester (Copley Scientific Limited, Nottingham, UK) while the mean friability of 20 tablets was obtained with a friabilator (Shivani Scientific Ind., Mumbai, India) set at 25 rpm for $4 \mathrm{~min}$. The time it took each tablet in distilled water maintained at 37 ${ }^{\circ} \mathrm{C}$ to disintegrate and go through the wire mesh of the disintegration test apparatus (Georgeon, Mumbai) was taken as the disintegration time. The results are given as mean of five determinations. Dissolution test for the tablets was determined using the Veego digital dissolution test apparatus (Veego, India). The dissolution medium used was 900 mLs phosphate buffer solution ( $\mathrm{pH}$ 6.8) maintained at $37 \pm 0.5^{\circ} \mathrm{C}$ and the rotating speed was $100 \mathrm{rpm}$. A $5 \mathrm{~mL}$ samples were withdrawn at 5, 10, 15, 30, 45 and 60 minutes and replaced with the same volume of fresh medium maintained at the same temperature. The samples withdrawn were filtered through Whatman filter paper and the absorbance of the samples was measured on the spectrophotometer at a wavelength of 233 $\mathrm{nm}$. The test was repeated thrice. 


\section{RESULTS AND DISCUSSION}

\section{Morphology, FTIR Characterization and thermal properties}

The scanning electron micrographs of the starch are presented in Figure 1. The native potato starch (NPS) are predominantly oval in shape with few granules having polygonal shape while the co-processed potato starch (CPS) had more irregular, oval, polygonal and large truncated ellipsoidal granules.

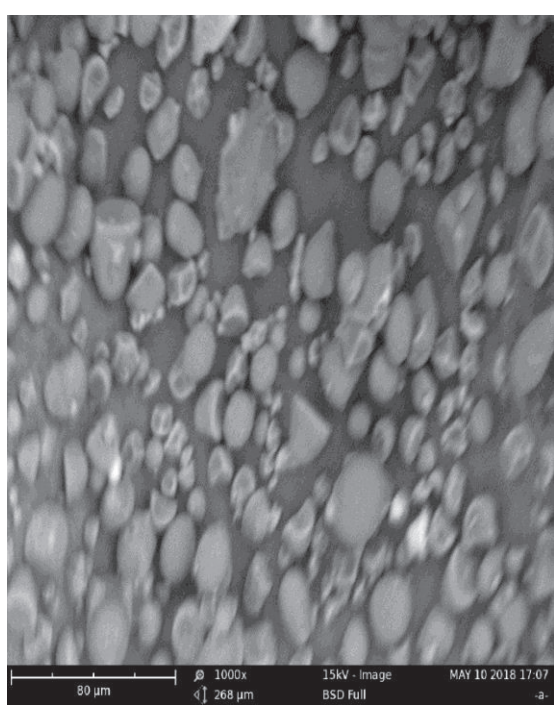

A. SEM of CPS

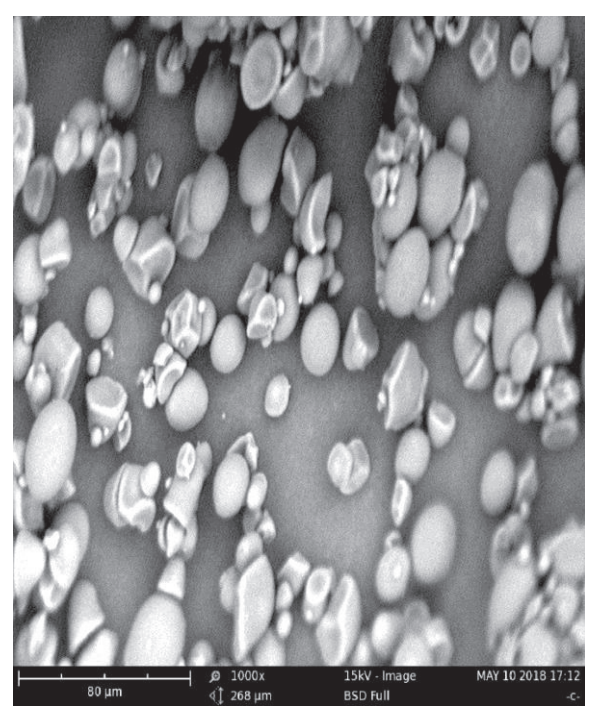

B. SEM of NPS

Figure 1. Scanning electron micrograph of CPS and NPS.

The FTIR spectra of native CPS reveal a broad band at $3265 \mathrm{~cm}^{-1}$ attributable to hydrogen bonded -OH (Figure 2). The stretching peak at $2928 \mathrm{~cm}^{-1}$ is due to $-\mathrm{CH}$ stretching vibration of the amylose and amylopectin present in the starch while the peak at $1640 \mathrm{~cm}^{-1}$ is characteristic of tightly bound water molecules ${ }^{17}$. 


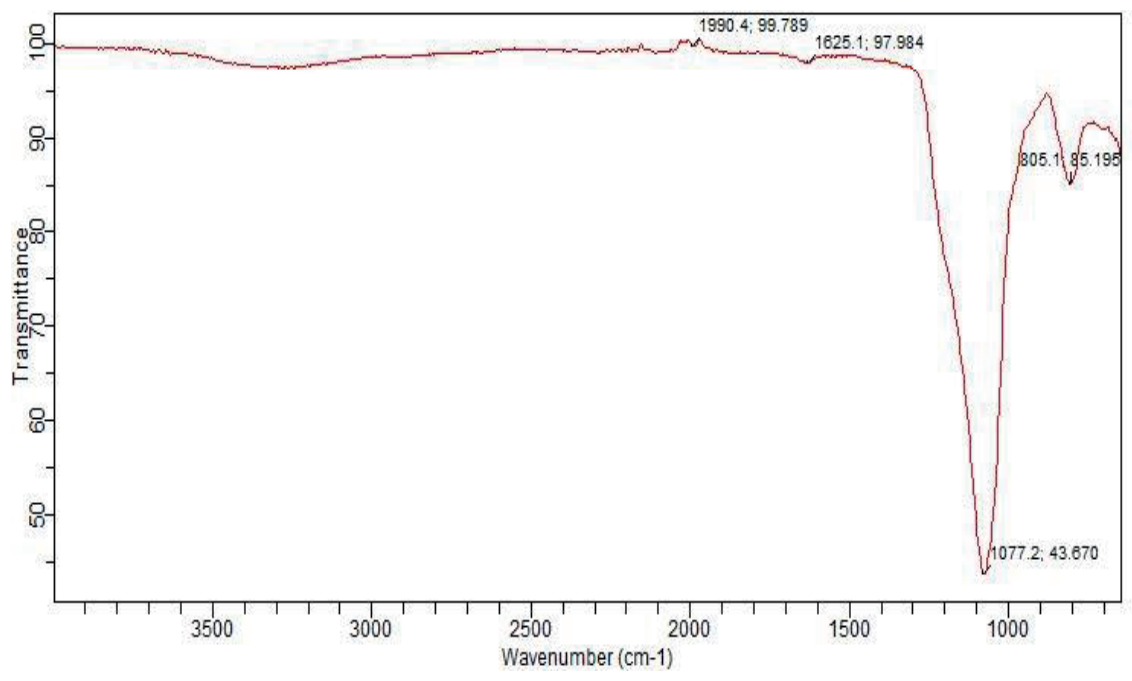

Figure 2a. FTIR spectrum of physical mixture of NPS and silicon dioxide.

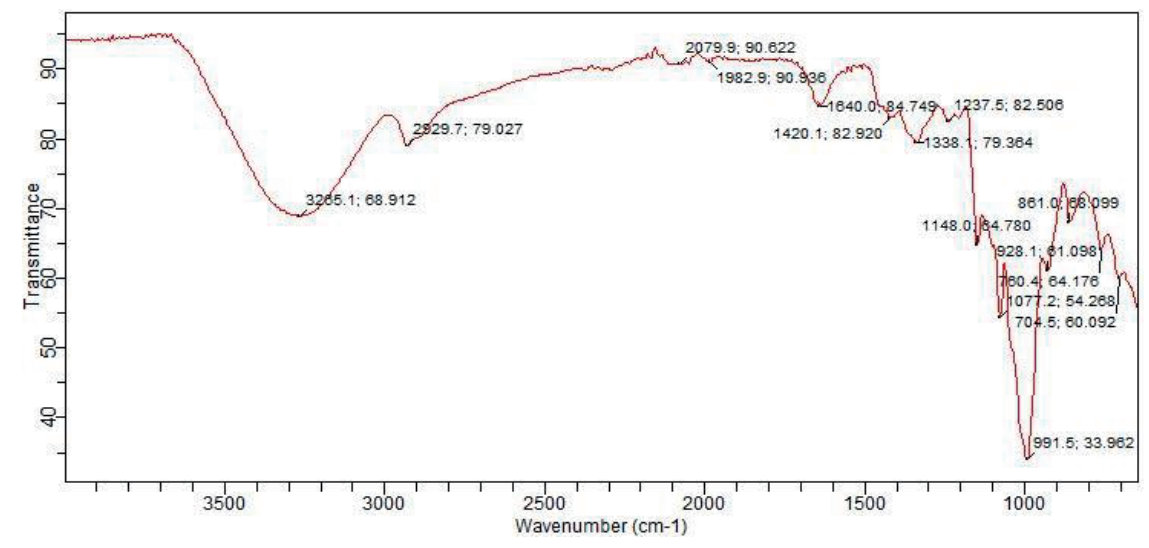

Figure 2b. FTIR spectrum of CPS.

The stretching peaks at 791 and $1077 \mathrm{~cm}^{-1}$ is due to the stretching modes in the amorphous regions of the starch ${ }^{18}$. The DSC thermograms presented in Figure 3 show that CPS and NPS exhibited single endothermic peak at $116{ }^{\circ} \mathrm{C}$ which is usually attributed to the melting of amylose- lipid complexes formed when the starches are heated in DSC ${ }^{19}$. These lipids are usually fatty acids and monoglycerides. Starch is a semicrystalline compound which comprises both amylose and amylopectin components. The linear structure of the amylose is responsible for the crystalline region while the amylopectin accounts for the amorphous phase ${ }^{20-22}$. 


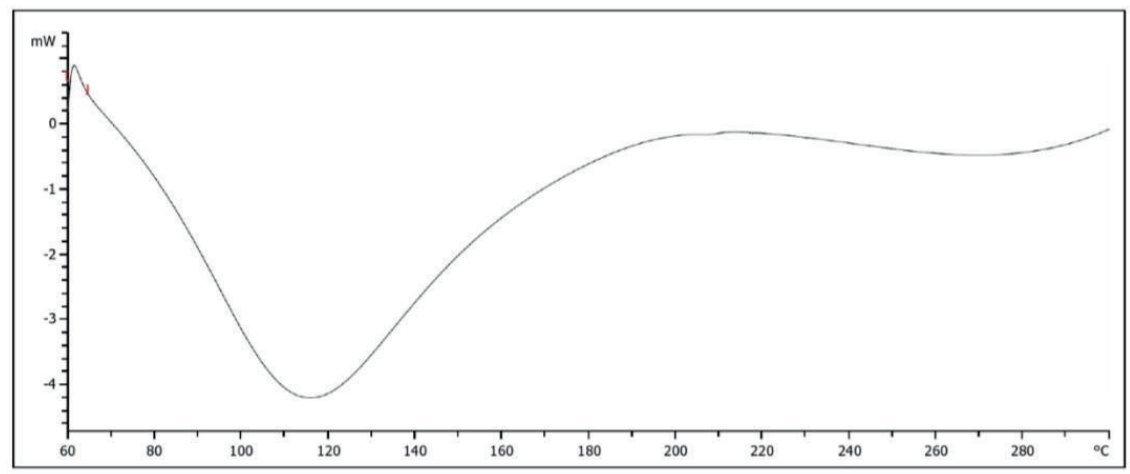

Figure 3a. DSC thermogram of CPS.

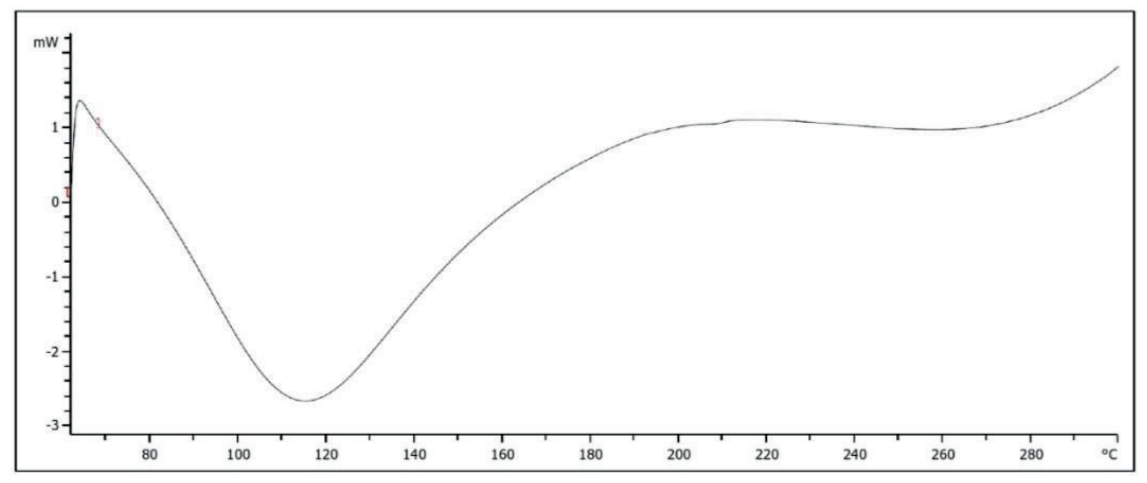

Figure 3b. DSC thermogram of NPS.

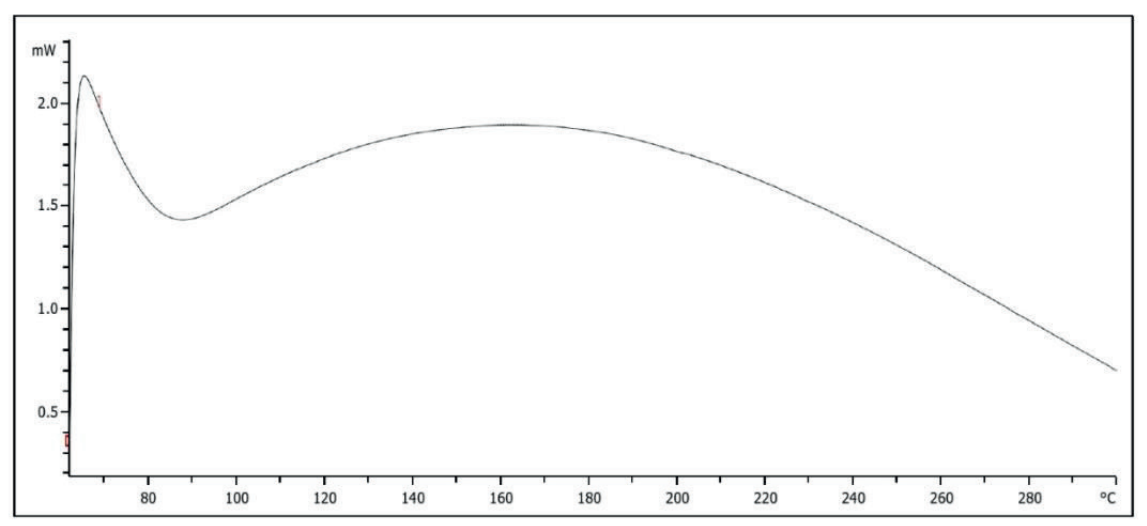

Figure 3c. DSC thermogram of physical mixture of NPS and colloidal silicon dioxide. 
Figure 4 which represents the XRD spectra of NPS and CPS confirm the existence of these two phases which is characterized by a broad region between $10^{\circ}$ and $27^{\circ} 2 \theta$ containing some distinctive reflections or peaks. Both NPS and CPS exhibited strong reflections at 15 and $24^{\circ} 2 \theta$ and an unresolved doublet at $18^{\circ}$ $2 \theta$ which is typical of a Type A XRD pattern. The CPS however has a sharp peak with strong intensity at $27^{\circ} 2 \theta$ which is absent in NPS. This could probably be due to a disruption in the granules structure as a result of heating due to co processing. The spectrum of the binary mixture of NPS and colloidal silicon dioxide appears noisy and the peaks are difficult to distinguish.

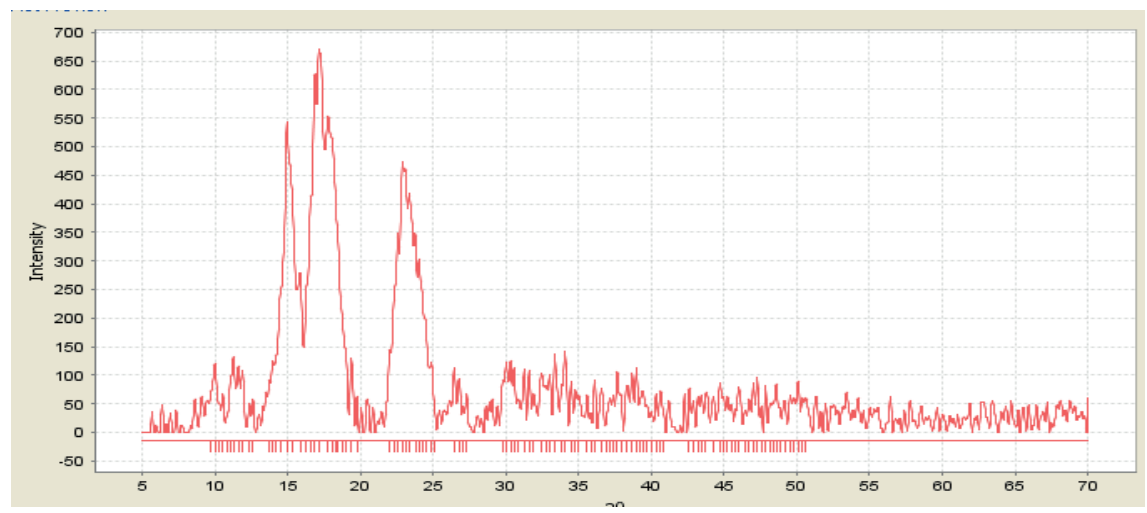

Figure 4a. XRD spectrum of NPS

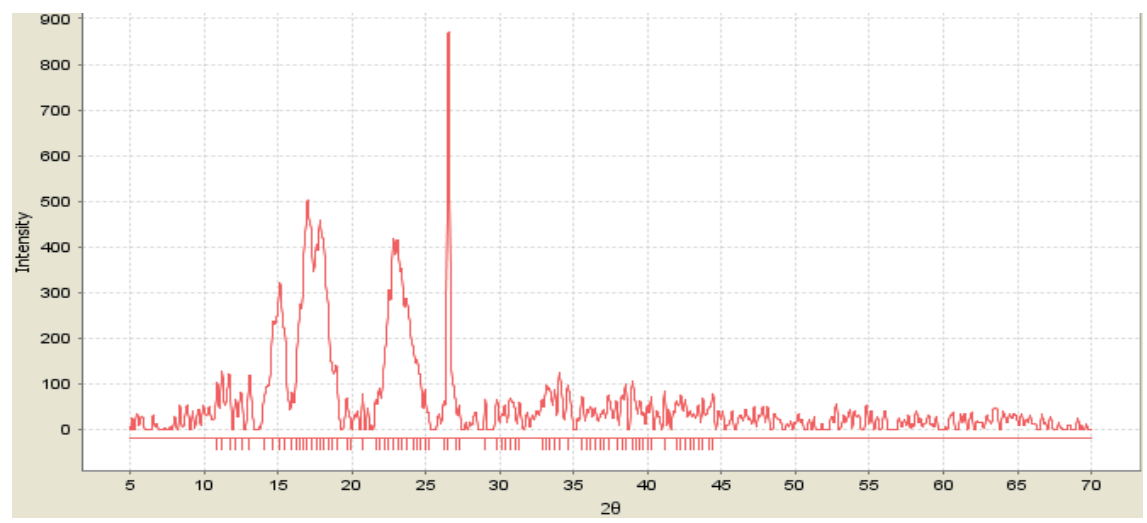

Figure 4b. XRD spectrum of CPS 


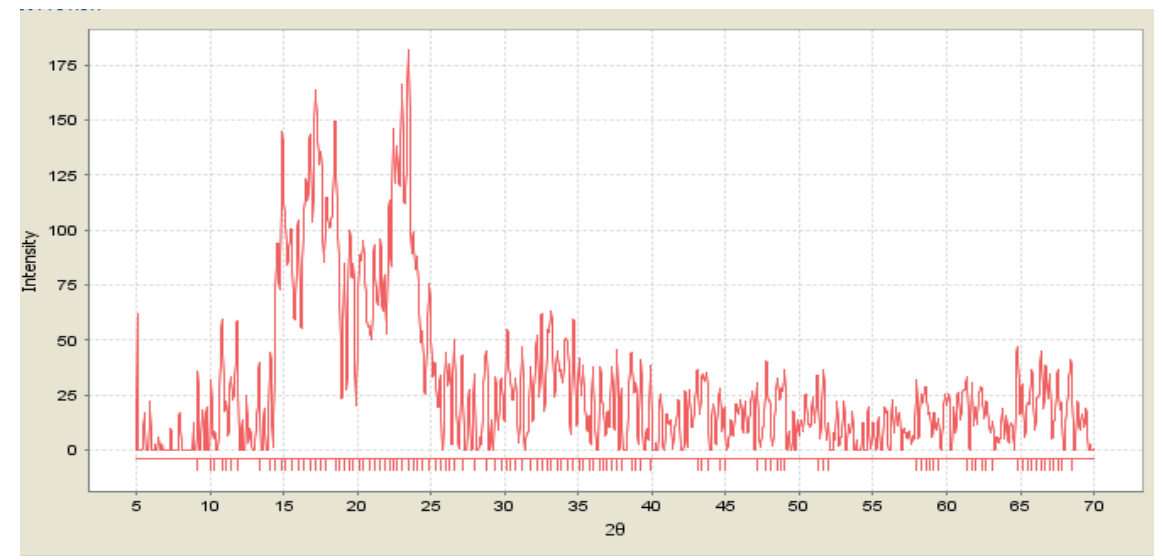

Figure 4c. XRD spectrum of binary mixture of NPS and colloidal silicon dioxide

\section{Physicochemical and compressional properties}

The physicochemical properties of pharmaceutical excipients are critical to the properties of the final formulation. Table 2 presents the powder properties of the starches. The angle of repose, Hausners ratio and compressibility index are parameters that indirectly measure the flowability of powders. Generally, materials with angle of repose below $30^{\circ}$, Hausners ratio less than 1.25 and compressibility index below $16 \%$ indicate good flow ${ }^{23}$.

Table 2. Powder properties of sample materials.

\begin{tabular}{llll}
\hline Properties & NPS & CPS & CS \\
\hline Particle density $\left(\mathrm{g} / \mathrm{cm}^{3}\right)$ & $1.103 \pm 0.01$ & $2.197 \pm 0.03$ & $0.819 \pm 0.01$ \\
Bulk density $\left(\mathrm{g} / \mathrm{cm}^{3}\right)$ & $0.56 \pm 0.12$ & $0.50 \pm 0.03$ & $0.41 \pm 0.10$ \\
Tapped density $\left(\mathrm{g} / \mathrm{cm}^{3}\right)$ & $0.62 \pm 0.05$ & $0.63 \pm 0.16$ & $0.56 \pm 0.20$ \\
Angle of repose $\left({ }^{\circ}\right)$ & 24.60 & 32.70 & 17.70 \\
Carr's index & 9.10 & 19.10 & 27.38 \\
Hausner ratio & 1.10 & 1.24 & 1.37 \\
Swelling index $(\%)$ & 12.0 & 12.9 & 6.35 \\
Porosity $(\%)$ & 51.1 & 22.9 & 51.20 \\
Moisture content $(\%)$ & 6.7 & 13.3 & 6.22 \\
Flow rate $(\mathrm{g} / \mathrm{s})$ & 2.50 & 3.61 & 0.13 \\
\hline
\end{tabular}


The rank for the angle of repose is CPS $>$ NPS $>$ CS. This suggests that co-processing with silicon dioxide did not improve the flow property. This is consistent with the SEM analysis which reveals that CPS has irregularly shaped particles. This increases inter-particulate friction and thus results in increased cohesive forces within the starch particles. Moreover, the high moisture content of CPS might also account for the higher angle of repose. The Hausners ratio and compressibility index values obtained are consistent with the reduction in powder flow in CPS. There was a slight increase in the swelling capacity after co-processing, but the bulk density decreased. The reduction in bulk density might be due to a less dense packing behavior as a result of the irregularly shaped particles. It is important to optimize the moisture content of powder materials because of its effect on stability of pharmaceutical formulations. CPS has high moisture content and requires further drying if it is to be employed in tablet manufacture. Figures 5 and 6 represents Heckel and Kawakita plots respectively. CPS exhibited a Heckel plot shape characteristic of a Type A materials which deforms plastically. The parameters derived from the plots are presented in Table 3. Microcrystalline cellulose (MCC) and dicalcium phosphate dihydrate (DCP) used in this study are model examples of plastically deforming and brittle materials respectively. The Heckel model relates the reduction in powder volume to the applied pressure. Py gives an indication of the plasticity and softness of the materials. A low value shows low resistance to pressure, good densification and fast onset of plastic deformation ${ }^{16}$. The rank order of Py is $\mathrm{DCP}<\mathrm{NPS}<\mathrm{MCC}<\mathrm{CPS}$. This suggests that NPS has a faster onset of plastic deformation than CPS. $\mathrm{D}_{\mathrm{B}}$ is the rearrangement phase at the early stages of compression. The ranking of $\mathrm{D}_{\mathrm{B}}$ is $\mathrm{CPS}>\mathrm{NPS}>\mathrm{MCC}>\mathrm{CS}$. The high values of $\mathrm{D}_{\mathrm{B}}$ in CPS is probably as result of particle de-segmentation. The total degree of densification occurring in a powder bed $\left(D_{A}\right)$ for CPS was more than NPS. The rank order of $\mathrm{P}_{\mathrm{k}}$ is $\mathrm{CPS}<\mathrm{NPS}<\mathrm{MCC}<\mathrm{DCP}$. This indicates that the overall plastic deformation was highest in CPS. 


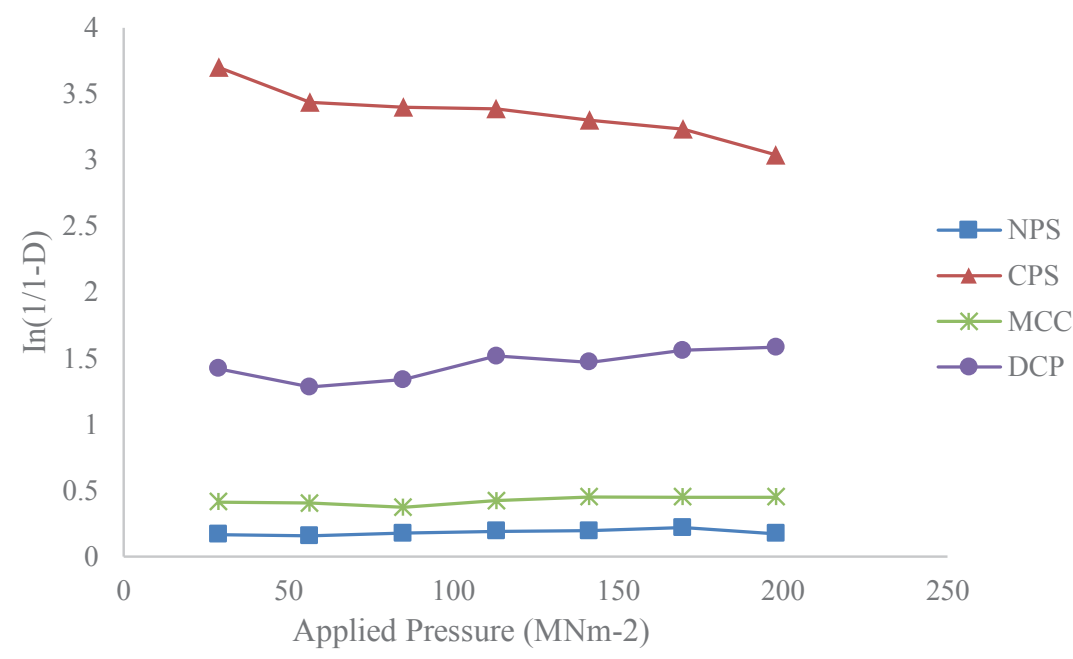

Figure 5. Representative Heckel plot.

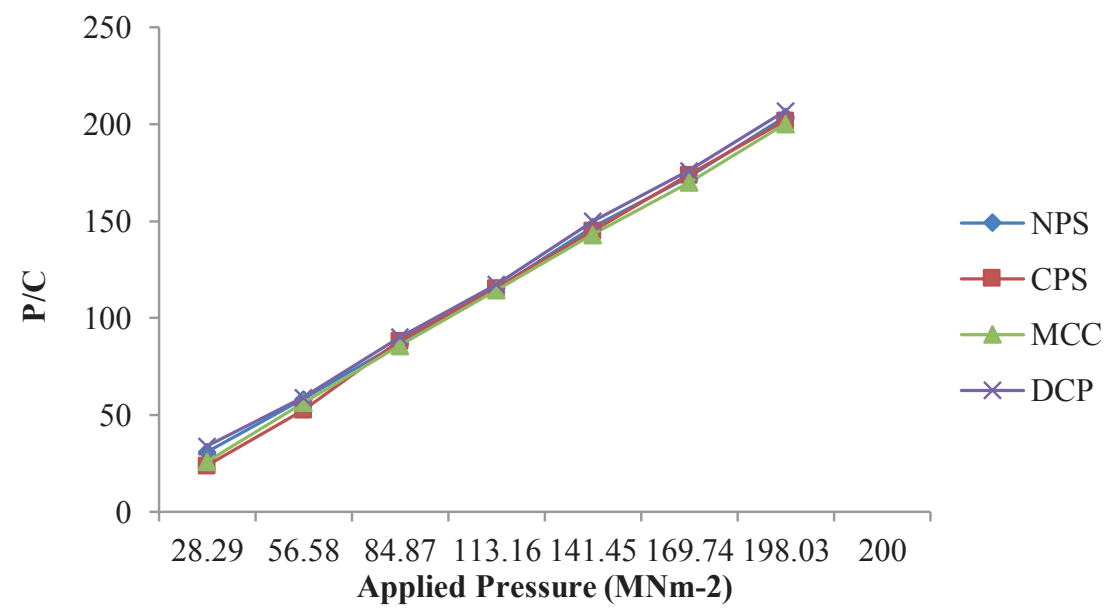

Figure 6. Representative Kawakita plot. 
Table 3. Parameters obtained from compression data analysis.

\begin{tabular}{lllll|llll}
\hline & \multicolumn{4}{c|}{ Heckel Parameters } & \multicolumn{4}{c}{ Kawakita Parameters } \\
\cline { 2 - 9 } Sample & $\mathrm{D}_{0}$ & $\mathrm{P}_{\mathrm{y}}$ & $\mathrm{D}_{\mathrm{A}}$ & $\mathrm{D}_{\mathrm{B}}$ & $\mathrm{a}$ & $\mathrm{D}_{\mathrm{I}}$ & $\mathrm{b}$ & $\mathrm{P}_{\mathrm{K}}$ \\
\hline NPS & 0.501 & 52.90 & 0.9220 & 0.501 & 0.2527 & 0.7473 & 0.2177 & 4.59 \\
\hline CPS & 0.074 & 250.00 & 0.1511 & 0.610 & 0.2547 & 0.7453 & 0.5646 & 1.77 \\
\hline DCP & 0.610 & 26.70 & 0.7240 & 0.074 & 0.2579 & 0.7421 & 0.0109 & 91.74 \\
\hline MCC & 0.087 & 116.27 & 0.4910 & 0.087 & 0.2517 & 0.7483 & 0.0334 & 29.94 \\
\hline
\end{tabular}

\section{Mechanical properties of metronidazole tablet formulations}

The summary of the properties of metronidazole tablets formulated with CPS and NPS are shown in Table 4. The uniformity of weight test is a reflection of the amount of active pharmaceutical ingredient (API) present in a formulation although it does not assure uniformity of the API in all the tablets particularly in low dose formulations. According to the USP "for tablets with weights greater than $324 \mathrm{mg}$, not more than two tablets should have weights that deviate from the average weight by more than $5 \%{ }^{24}$. Only formulations containing $40 \% \mathrm{w} / \mathrm{w}$ CPS and $50 \% \mathrm{w} / \mathrm{w}$ NPS met the compendia specification. Tablets should have enough mechanical strength in order to be able withstand the stress encountered during packaging, transportation and handling. The crushing strength and friability are important parameters that have been used to assess the mechanical strength of tablet formulations ${ }^{25}$. A tablet must have a crushing strength of not less than $4 \mathrm{~kg}$ to be considered of satisfactory mechanical strength ${ }^{26}$. The results show that all the formulations have satisfactory strength except formulations containing $40 \% \mathrm{w} / \mathrm{w}$ CPS. The friability test measures the physical strength of tablets on exposure to attrition or mechanical shock. Conventionally, friability values less than $1 \%$ are considered acceptable ${ }^{23}$. Table 4 shows that all the formulations did not meet the specification and tablets containing CPS are more friable than those formulated with NPS. The crushing strength - friability ratio (CSFR) can also be used to assess the mechanical strength of tablets. Generally, the higher the CSFR, the stronger the tablet (Bakre and Sholuade, 2018). Tablets containing NPS were stronger than formulations containing CPS. All the formulations had disintegration time lower than the British Pharmacopeia ${ }^{28}$ specification of 15 min for uncoated tablets. However, tablets formulated with NPS disintegrated faster than formulations having CPS. Generally, formulations containing $40 \%$ w/w starch had lower disintegration time than those containing $50 \% \mathrm{w} / \mathrm{w}$ starch. 
Table 4. Tableting parameters of metronidazole formulations.

\begin{tabular}{lllccccc}
\hline $\begin{array}{l}\text { Formation } \\
\text { Code }\end{array}$ & $\begin{array}{l}\text { Uniformity } \\
\text { of weight } \\
(\mathbf{m g})\end{array}$ & $\begin{array}{l}\text { Crushing } \\
\text { Strength } \\
(\mathbf{k g} / \mathrm{cm})\end{array}$ & $\begin{array}{l}\text { Friability } \\
(\%)\end{array}$ & $\begin{array}{l}\text { Disintegration } \\
\text { Time } \\
\text { (secs) }\end{array}$ & CSF & $\begin{array}{l}\mathrm{T}_{50} \\
\text { (secs) }\end{array}$ & $\begin{array}{c}\mathrm{T}_{90} \\
\text { (secs) }\end{array}$ \\
\hline A & $0.401 \pm 0.42$ & $4.33 \pm 0.23$ & $12.1 \pm 0.03$ & $50 \pm 0.01$ & 0.36 & 23.9 & 42.9 \\
B & $0.393 \pm 0.05$ & $1.83 \pm 0.05$ & $11.4 \pm 0.15$ & $23 \pm 0.13$ & 0.16 & 45.7 & 84.1 \\
C & $0.395 \pm 0.03$ & $4.67 \pm 0.01$ & $10.1 \pm 0.04$ & $21 \pm 0.04$ & 0.46 & 26.0 & 53.8 \\
D & $0.393 \pm 0.11$ & $5.33 \pm 0.03$ & $10.0 \pm 0.14$ & $19 \pm 0.06$ & 0.53 & 96.5 & 182.6 \\
\hline
\end{tabular}

\section{In vitro release properties}

The dissolution profile of the metronidazole formulations containing NPS and CPS is shown in Figure 7. The result (Table 4) shows that the rank order of the time taken for 50\% $\left(\mathrm{T}_{50}\right)$ and $90 \%\left(\mathrm{~T}_{90}\right)$ drug release was $\mathrm{A}<\mathrm{C}<\mathrm{B}<\mathrm{D}$. Tablets formulated with CPS had faster dissolution than those containing similar concentration of NPS. In addition, the effect of CPS and NPS on dissolution was concentration dependent i.e formulations containing $50 \% \mathrm{w} / \mathrm{w}$ starch had faster dissolution than those formulated with $40 \% \mathrm{w} / \mathrm{w}$ starch.

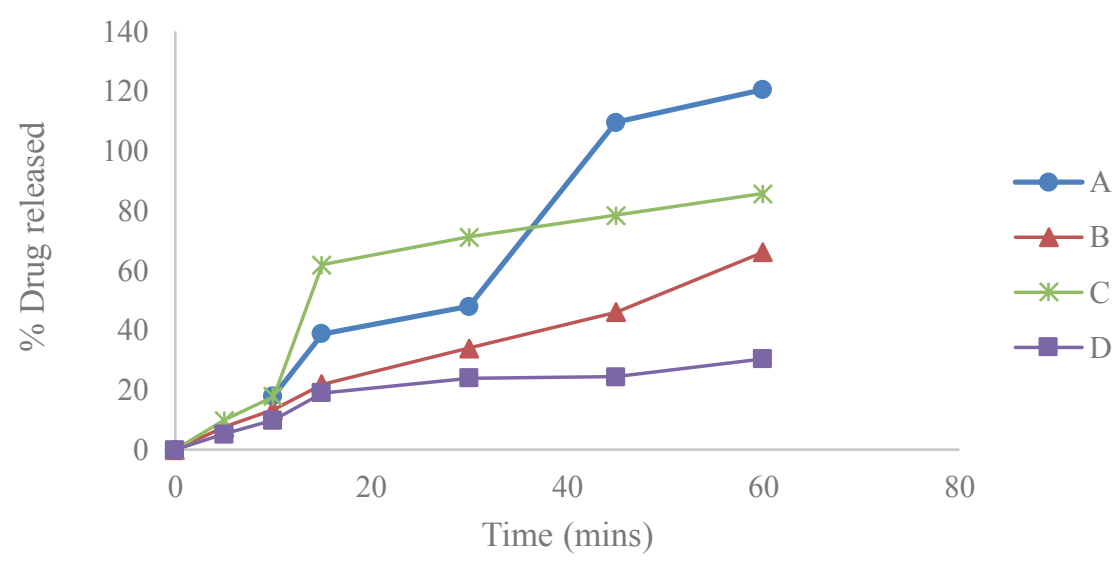

Figure 7. Representative plots of dissolution profile of metronidazole formulations.

Co-processing of potato starch with silicon dioxide represents a simple derivatization procedure that has augmented the compressional and tableting characteristic of the native starch. Although metronidazole tablets containing the co-processed excipient had low mechanical strength, they exhibited faster dissolution than tablets containing similar concentration of the native starch.

\section{CONFLICT OF INTEREST}

The authors declare that they don't have any conflict of interest. 


\section{REFERENCES}

1. Abdellah A.; Noordin M. I.; Ismail W. A. Importance and globalization status of good manufacturing practice (GMP) requirements for pharmaceutical excipients. Saudi Pharm. J. 2015, $23,9-13$.

2. Zhou Q.; Shi L.; Chattoraj S.; Sun C.C. Preparation and characterization of surface-engineered coarse microcrystalline cellulose through dry coating with silica nanoparticles. $J$. Pharm. Sci. 2012, 101, 4258-4266.

3. Koo O.M.Y.; Squibb B. Application challenges and examples of new excipients in advanced drug delivery systems. Am. Pharm. Rev. 2011, 14, 60-68.

4. Builders P. F.; Mbah C. C.; Mohammed B. B. Preparation and evaluation of carbopol coated maize starch: A novel multifunctional excipient. Afr. J. Pharm. Pharmacol. 2017, 11, 458-469.

5. Gohel M. C.; Jogani P. D. A review of co-processed directly compressible excipients. J Pharm. Pharm. Sci. 2015, 8, 76-93.

6. Adetunji O. A.; Odeniyi M. A. Material and compression properties of Cedrela odorata gum co-processed with plantain starch and microcrystalline cellulose. Polim. Med. 2016, 46, 35-43.

7. Mshelia J. G.; Apeji Y. E.; Olayemi O. J. Powder, compaction and tableting properties of coprocessed silicified starch. British J Pharm. Res. 2015, 6, 131-140.

8. Rojas J.; Kumar V. Comparative evaluation of silicified microcrystalline cellulose II as a direct compression vehicle. Int. J. Pharm. 2011, 416, 120-128.

9. Daraghmeh N.; Rashid I.; Al Omari M. M. H.; Leharne S. A.; Chowdhry B. Z.; Badwan A. Preparation and characterization of a novel co-processed excipient of chitin and crystalline mannitol. AAPS Pharm. Sci. Tech. 2010, 11, 1558-1571.

10. Builders P. F.; Arhewoh M. I. Pharmaceutical applications of native starch in conventional drug delivery. Starch. 2016, 68, 864-873.

11. Alebiowu G. Steeping period influence on physical, compressional and mechanical properties of tapioca starch. J. Pharm. Res. 2007, 6, 139-144.

12. Bakre L. G.; Ajala J. Preliminary evaluation of the physicochemical properties of maize husk, maize silk and cellulose derived from maize husk. Nig. J. Pharm. Sci. 2012, 11, 21-30.

13. British Standard 1469. British Standard Institution: London. 1970.

14. Heckel R.W. Density-pressure relationship in powder compaction. Trans Metal Soc. AIME. 1961, 221.

15. Kawakita K.; Ludde K. H. Some considerations on powder compression equations. Powder Technol. 1971, 4, 61-68.

16. Bakre L. G.; Osideko A.O.; Bamiro O. A. Isolation and characterization of a plant gum from Chrysophyllum albidium fruits as pharmaceutical excipient. J Pharm. Biores. 2017, 14, 22-30.

17. Fang J. M.; Fowler P. A.; Tomkinson J.; Hill C. A. S. The preparation and characterization of series of chemically modified potato starches. Carbohydr. Polym. 2002, 47, 245-252.

18. Van Soest J. J. G.; Tournois H.; de Wit D.; Vliegenthart J. F. G. Short range structure in (partially) crystalline potato starch determined with attenuated total reflectance Fourier-transform IR spectroscopy. Carbohydr. Res. 1995, 27, 201-214.

19. Biliaderis C. G. Structures and phase transitions of starch in food systems. Food Technol. 1992, 6, 98-109.

20. Liu H.; Yu L.; Xie F.; Chen L. Gelatinization of cornstarch with different amylose/amylopec- 
tin content. Carbohydrate Polym. 2006, 65, 357-363.

21. Jane J. Current understanding on starch granule structures. J. Appl. Glycosci. 2oo6, 53, 205-213.

22. Tester R. F.; Karkalas J.; Qi X. Starch-composition, fine structure and architecture. J. Cereal Sci. 2004, 39, 151-165.

23. Kwabena O.; Kwadwo A. M.; Samuel L. K.; Noble K.; Mariam E. B. Development and evaluation of natural gum-based extended release matrix tablets of two model drugs of different water solubilities by direct compression. Saudi Pharm. J. 2016, 24, 82-91.

24. United States Pharmacopoeia and National Formulary, 2007. United States Pharmacopoeia XXIII: Rockville U.S.P Convention Inc.

25. Kaleemullah M.; Jiyauddin K.; Thiban E.; Rasha S.; Al-Dhalli S.; Budiasih S.; Gamal O.E.; Fadli A.; Eddy Y. Development and evaluation of Ketoprofen sustained release matrix tablet using Hibiscus rosa-sinensis leaves mucilage. Saudi Pharm. J. 2017, 25, 770-779.

26. Majekodunmi S. O.; Lori E. Lubricating properties of co-processed coconut oil in paracetamol tablets formulation. British J. Pharm. Res. 2016, 14, 1-10.

27. Bakre L. G.; Sholuade T.O. Formulation and In Vitro Evaluation of Ciprofloxacin Matrix Tablets: Effect of Drug-Polymer Ratio. Trop. J. Nat. Prod. Res. 2018, 2, 250-253.

28. British Pharmacopoeia Vol. 4. Her Majesty Stationery Office, London. 2003; 2051. 